\title{
Intraoperative monitoring of the facial nerve in parotid surgery
}

\author{
R. Hainăroşie ${ }^{1,2}$, Mura Hainăroşie ${ }^{2}$, O. Ceachir², Irina Ioniță², Cătălina Pietroşanu ${ }^{1,2}$, \\ Carmen Drăghici ${ }^{1}$, Cristina Zamfir ${ }^{1}$, V. Zainea ${ }^{1,2}$
}

Corresponding author:

Octavian Ceachir, MD

"Prof. Dr. D. Hocioty" Institute of

Phonoaudiology and Functional ENT

Surgery, $21^{\text {st }}$ Mihail Cioranu Street,

$5^{\text {th }}$ District, Bucharest, Romania

E-mail: octavianceachir@gmail.com
${ }^{1}$ Institute of Phonoaudiology and Functional ENT Surgery - Prof. Dr. Dorin Hociota,

Bucharest, Romania

2"Carol Davila" University of Medicine and Pharmacy, Bucharest, Romania

\section{ABSTRACT}

The purpose of this article is to analyse the facial nerve electrophysiological monitoring effective ness in preventing injuries of this nerve during parotid surgery. To achieve this goal we analysed relevant data available in the literature on both the surgical technique and intraoperative continuous monitoring principles. In order to draw the conclusions of this paper we correlated the obtained data with our own experience.

Key words: facial nerve, electrophysiological monitoring, parotid surgery

\section{BACKGROUND}

Parotidectomy is a well standardized surgical procedure, usually performed by the ENT head and neck surgeons or the oral and maxillofacial surgeons, for benign and malignant conditions of the parotid gland (1).

The peripheral branches of the facial nerve are in close contact with the parotid gland, so one of the most important and feared complication of this type of surgery is represented by this nerve's injury, during surgical dissection. This can occure through mechanical (sectioning, stretching, compressing the nerve), thermal or electrical injuries or ischemia, leading to temporary or permanent nerve disfunction, with important functional and aesthetic prejudices.

Nerve monitoring systems are designed to locate and identify cranial and peripheral motor and mixed motor-sensory nerves during surgery, including spinal cord and spinal nerve roots. The target nerves are stimulated periodically by an electric current of low intensity. These systems can be used in intracranial, extracranial, intratemporal, extratemporal surgery, neck dissections, thoracic surgeries and surgical procedures on the upper and lower limbs.

Being based on EMG responses to direct or passive nerve stimulation, a monitoring device can't be used during anesthesia with paralyzing agents because these substances will completely annihilate the response to stimulation, transforming the device into a redundant one (2). 
Intraoperative nerve monitoring of the facial nerve is widely used in otologic, neurotologic and skullbase surgery, its effectiveness, in these types of surgeries, being proven over the years. The use of facial nerve monitoring in parotid surgery has the same goals as in the other types of surgery, previously described. It's main purpose is to reduce the risk of damage to the facial nerve during total or partial parotidectomy. Although temporary dysfunction of the facial nerve following parotidectomy is relatively common, facial paralysis occurs in less than $5 \%$ of patients, in most cases this being the result of difficult surgical dissection due to large tumors, scar tissue from previous surgical procedures or repeated inflammatory outbursts (3-9).

Even if the percentage of $5 \%$ may seem small at first glance, the impact of facial paralysis at an individual level can be devastating, as a consequence of the functional and aesthetic prejudice. Psychologically, each patient deals in a different way with this condition, psychiatric disorders from anxiety to paranoia being reported after facial paralysis (10-11). No correlation between the degree of dysfunction and functional damage could be demonstrated (11).

A study conducted in the U.S. showed that the surgeons using a facial nerve monitoring system were less likely to have a malpractice lawsuit related to parotid surgery (12).

\section{SURGICAL TECHNIQUE}

Parotidectomy can be superficial, partial, deep lobe, total or extended. In choosing the type of parotidectomy that has to be performed, the surgeon's experience is crucial - "Surgeons will spend their entire career trying to learn when it is safe or necessary to do more or less than a superficial parotidectomy" (Variations of Parotidectomy - Indications and Technique, Kerry D. Olsen, M.D. Professor and Chairman, Head and Neck Surgery, Mayo Clinic).

This procedure is indicated in benign or malignant tumors of the gland, malignant tumors of the skin covering the gland, chronic parotiditis refractory to medical or minimally invasive treatment (sialendoscopy), in the complications following sialendoscopy and for the resection of lymph nodes at risk for metastases (13).

This type of surgery is contraindicated in patients with important comorbidities, when general anesthesia can't be administered.

The goals of parotidectomy are to remove safely and completely the lesion (following the principles of oncologic surgery), to preserve the function of the facial nerve and, if it is possible, to preserve the posterior branch of the greater auricular nerve.

In order to achieve these goals the facial nerve must be identified and safely dissected by an anterograde or retrograde approach. The anterograde approach seems to be the most commonly used technique of identification and dissection of the facial nerve (14). The first step for avoiding this type of lesions consists in safely identifying the trunk of the facial nerve as it exits the skull through the stilomastoid foramen, at the level of the tympanomastoid suture, tragal pointer or posterior belly of the digastric muscle (15). In order to expose the trunk of the facial nerve at the level of the stylomastoid foramen, the dissection should pass down the avascular plane situated between the body of the parotid gland and the external acoustic canal. The dissection should be continued to the jonction of the bony canal with the cartilaginous one (16). Usually, an extension of the cartilage points towards the place where the facial nerve leaves the stilomastoid foramen. The facial nerve can be discovered through an anterograde approach at about $9 \mathrm{~mm}$ from the posterior belly of the digasstric muscle and $11 \mathrm{~mm}$ from the bony external meatus (Holt 1996).

The retrograde approach is based on the identification of the peripheral branches of the facial nerve based on soft tissue surgical landmarks. In this type of approach a nerve monitor can be used, providing an easier way of identifying the ramifications of the facial nerve (17).

\section{Facial monitoring}

Facial nerve monitoring during parotid surgery has been done in multiple ways over the years, from watching facial movement determined by electric or mechanic stimulation by the surgeon to "state of the art technology" - EMG of the face with 8 channels neuro monitors.

Yet none of the methods described above can replace a judicious surgical dissection, following well-defined surgical landmarks, and not at least, the personal experience of the surgeon in this type of surgery.

The main roles of monitoring the facial nerve are: reducing the risck of iatrogenic trauma during dissection, mapping the course of the nerve, early nerve identification and warning the surgeon about the proximity of the nerve during dissection (18).

Usually there are four electrodes inserted in the skin of the face inervated by the peripheric branches of facial nerve: frontal, zygomatic, buccal and mandibular, one ground electrode and a sterile probe that can be inserted in the surgical field. The role of this device is to 


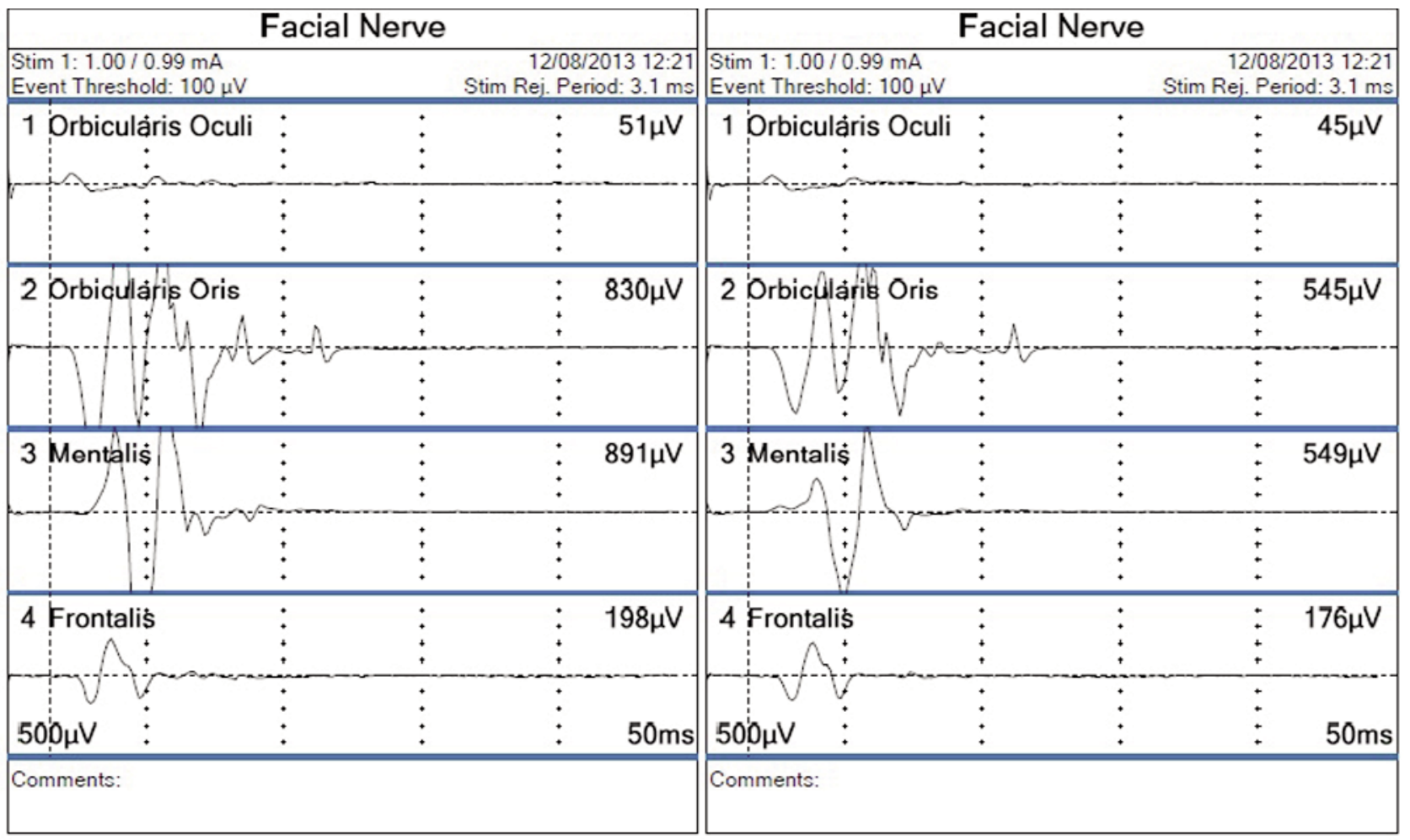

Figure 1

identify the main trunk of the facial nerve, to differentiate the facial nerve and/or branches from sensory nerves and to stimulate the areas that are found in the vicinity of the facial branches with an electric current of $0,5 \mathrm{~mA}$ intensity and a duration of 100 microseconds. Another parameter used is the event treshold, that is set at 100 microvolts, figure 1 (19).

Although in the US and Great Britain nerve monitoring is used in almost every parotidectomy, some authors consider that it has specific aplications, usually in situations when the risk of nerve damage is higher than normal: parotid revision surgery, previously iradiated patients, large malignant tumors or chronic parotiditis (20-22).

Various reports from literature show different data about the benefits of intraoperative monitoring of the facial nerve: Wolf et al. reports a decrease in the operative time and an increase in facial function preservation, Terell et al. published a study performed on 117 patient that showed no difference between the study group and the control group, intraoperative time or incidence of permanent facial paralysis $(23,24)$. In 1998 Witt reported a retrospective study on 53 patients that proved no improvement in the outcomes of the parotid surgery when using facial monitoring (25). Lopez et al., Doikov et al., Makeieff et al. and Wang et al. observed positive results in patients that underwent different types of parotidectomy with facial nerve monitoring, regarding the incidence of temporary or permanent facial paralysis and the period of time necessary for the temporary facial paralysis to recover (26-29).

\section{CONCLUSIONS}

By reviewing the data from the literature completed with our experience we believe that facial nerve monitoring in parotid surgery is an adjunctive method that can guide the surgeon during difficult dissections but can not replace a good knowledge of the local anatomy or his experience.

Also, we consider that by using the continous electrophysiologic facial nerve monitoring, the patient can be reassured that every method and device available is used for his/her welfare, reducind in this way the risk of a malpractice related lawsuit.

\section{REFERENCES}

1. Adeyemo WL, Taiwo OA, Somefun OA, Olasoji HO, Ndukwe KC, Fashina $A A$, Alabi BS A survey of facial nerve dissection techniques in benign parotid surgery among maxillofacial and ear, nose, and throat surgeons in Nigeria. Nigerian Journal of Clinical Practice 2011; 14(1):83-87

2. Theide 0 , Klusener $\mathrm{T}$, Sielenkamper $\mathrm{A}$, et al. Interference between muscle relaxation and facial nerve monitoring during parotidectomy. Acta Otolaryngol 2006; 126:422-428.

3. Nouraei SA, Ismail Y, Ferguson MS, et al. Analysis of complications 
following surgical treatment of benign parotid disease. ANZ J Surg 2008;73:134-138.

4. Upton DC, McNamar JP, Connor NP, et al. Parotidectomy: ten-year review of 237 cases at a single institution. Otolaryngol Head Neck Surg 2007;136:788-792.

5. Gaillard C, Perie S, Susini B, St. Guily JL. Facial nerve dysfunction after parotidectomy: the role of local factors. Laryngoscope 2005;115:287-291.

6. Guntinas-Lichius 0 , Klussmann JP, Wittekindt C, Stennert E. Parotidectomy for benign disease at a university teaching hospital: outcome of 963 operations. Laryngoscope 2006;116:534-540.

7. Witt RL. Facial nerve function after partial superficial parotidectomy: an 11 year review (1987-1997). Otolaryngol Head Neck Surg 1999;121: 210-213.

8. Bron LP, O'Brien CJ. Facial nerve function after parotidectomy. Arch Otolaryngol Head Neck Surg 1997;123:1091-1096.

9. Leverstein $\mathrm{H}$, van der Wal JE, Tiwari RM, et al. Surgical management of 246 previously untreated pleomorphic adenomas of the parotid gland. $\mathrm{Br} \mathrm{J}$ Surg 1997;84:399-403.

10. Macgregor FC: Facial disfigurement: Problems and management of social interaction and implications for mental health. Aesth Plast Surg 1990; 14 249-257.

11. Twerski A, Twerski B: The emotional impact of facial paralysis, in May M (ed): The Facial Nerve. New York, Thieme Inc., 1986, pp 788-794.

12. Lowry TR, Gal TJ, Brennan JA. Patterns of use of facial nerve monitoring during parotid gland surgery. Otolaryngol Head Neck Surg 2005;133: 313-318.

13. Parotidectomy with Facial Nerve Dissection - lowa Head and neck Protocols. https://wiki.uiowa.edu

14. Chan S, Gunn A. Conservative parotidectomy by the peripheral approach Br J Surg 1981;68:405-7. Back to cited text no. 3

15. Bhattacharyya N, Richardson ME, Gugino LD. An objective assessment of the advantages of retrograde parotidectomy. Otolaryngol Head Neck Surg 2004;131:393-6.

16. Carlson E. R., Ord R. A. Textbook and Color Atlas of Salivary Gland Pathology - Diagnosis and Management. Ed. Blackwell-Munskgaard,
2008:6-7.

17. Wang DZ, Liu SJ, Donoff RB, Guralnick W. A modified centripetal approach to parotidectomy. J Oral Maxillofac Surg 1985;43:14-9.

18. Silverstein $\mathrm{H}$, Rosenberg $\mathrm{S}$. Intraoperative facial nerve monitoring. Otolaryngol Clin North Am 1991;24:709-725.

19. Eisele D.W., Wang S.J., Orloff L.A. Electrophysiologic facial nerve monitoring during parotidectomy. Head Neck. 2010; 32(3):399-405.

20. Lowry TR, Gal TJ, Brennan JA. Patterns of use of facial nerve monitoring during parotid gland surgery. Otolaryngol Head Neck Surg 2005;133: 313-318.

21. Hopkins C, Khemani S, Terry RM, Golding-Wood D. How we do it; nerve monitoring in ENT surgery: currentUK practice. Clin Otolaryngol 2005; 30:195-198.

22. O'Regan B, Bharadwaj G, Elders A. Techniques for dissection of the facial nerve in benign parotid surgery: across specialty survey of oral and maxillofacial and ear nose throat surgeons in the UK. Br J Oral Maxillofac Surg 2008; 46:564-566.

23. Wolf SR, Schneider W, Suchy B, Eichhorn B. Intraoperative facial nerve monitoring in parotid surgery. HNO 1995;43:294-298.

24. Terrell JE, Kileny PR, Yian C, et al. Clinical outcome of continuous facial nerve monitoring during primary parotidectomy. Arch Otolaryngol Head Neck Surg 1997; 157:1081-1087.

25. Witt RL. Facial nerve monitoring in parotid surgery: the standard of care? Otolaryngol Head Neck Surg 1998;119:468-470.

26. Lopez M, Quer M, Leon X, et al. Usefulness of facial nerve monitoring during parotidectomy. Acta Otorrinolaringol Esp 2001;52:418-421.

27. Doikov IY, Konsulov SS, Dimov RS. Stimulation electromyography as a method of intraoperative localization and identification of the facial nerve during parotidectomy: review of 15 consecutive parotid surgeries. FoliaMed (Plovdiv) 2001;43:23-26.

28. Makeieff M, Venail F, Cartier C, et al. Continuous facial nerve monitoring during pleomorphic adenoma recurrence surgery. Laryngoscope 2005;115:1310-1314.

29. Wang $Z$, Wu H, Huang Q, et al. Facial nerve monitoring in parotid gland surgery. Lin Chuang Er Bi Yan Hou Ke Za Zhi 2006;20:436-437. 